\title{
stroses IBERO-AMERICANOS
}

\section{Sobre a Tropicália e outras artes: conflitos estéticos e debates em torno da nomeação da cultura brasileira (1982-2012)}

\author{
About Tropicália and other arts: aesthetic conflicts and debates around \\ the nomination of the Brazilian culture (1982-2012) \\ Sobre la Tropicália e otras artes: conflictos estéticos y debates en torno \\ a la designación de la cultura brasileña (1982-2012)
}

Fábio Leonardo Castelo Branco Brito*

\begin{abstract}
Resumo: Este artigo pretende realizar um balanço de diferentes discursos produzidos a respeito da cultura brasileira contemporânea entre o início da década de 1980 e o início da década de 2010. Na medida em que, no período recortado, houveram atravessamentos que marcaram as releituras de diversos movimentos culturais de afirmação nacional, dentre os quais o chamado movimento tropicalista, pretende-se observar diferentes percepções a respeito do espólio deixado pela iniciativa. Nesse sentido, materiais hemerográficos, ensaios acadêmicos ou não-acadêmicos, , iniciativas musicais e rastros de memórias constituem suportes que ajudam a perceber os diferentes esforços de significação do ser da cultura nacional. O artigo busca, a partir da análise de discursos, vistos como produtores de sentido no cotidiano, proposta por Mary Jane Spink e Benedito Medrado, perceber em que medida os movimentos culturais brasileiros produziram determinados lugares de poder na tentativa de definir uma identidade brasileira, e, consequentemente, lacunas em sua constituição e afirmação.
\end{abstract}

Palavras-chave: História; Cultura Brasileira; Identidade Nacional; Tropicália; Discursos.

Abstract: This article intends to make a balance of different discourses produced about contemporary Brazilian culture between the beginning of the 1980s and the beginning of the decade of 2010. In the cut-off period, there were crossings that marked the re-readings of various cultural movements of national affirmation, among which the so-called tropicalist movement, we intend to observe different perceptions regarding the estate left by the initiative. In this sense, hemerographic materials, academic or non-academic essays, musical initiatives and traces of memories constitute supports that help to perceive the different efforts of meaning of the being of the national culture. From the analysis of discourses, viewed as producers of meaning in everyday life, proposed by Mary Jane Spink and Benedito Medrado, the article seeks to understand the extent to which Brazilian cultural movements have produced certain places of power in an attempt to define a Brazilian identity, and, consequently, gaps in its constitution and affirmation.

Keywords: History; Brazilian Culture; National Identity; Tropicália; Speeches.

Resumen: Este artículo pretende realizar un balance de diferentes discursos producidos respecto a la cultura brasileña contemporánea entre el inicio de la década de 1980 y el inicio de la década de 2010. En la medida en que, en el período recortado, hubo atravesamientos que marcaron las relecturas de diversos movimientos culturales de afirmación nacional, entre los cuales el llamado movimiento tropicalista, se pretende observar diferentes percepciones acerca del botín dejado por la iniciativa. En ese sentido, materiales hemerográficos, ensayos académicos o no académicos, iniciativas musicales y rastros de memorias constituyen soportes que ayudan a percibir los diferentes esfuerzos de significación del ser de la cultura nacional. El artículo busca, a partir del análisis de discursos, vistos como productores de sentido en el cotidiano, propuesta por Mary Jane Spink y Benedito Medrado, percibir en qué medida los movimientos culturales brasileños produjeron determinados lugares de poder en el intento de definir una identidad brasileña, y, en consecuencia, lagunas en su constitución y afirmación.

Palabras clave: Historia; Cultura Brasileña; Identidad Nacional; Tropicália; Discursos.

* Doutor em História Social pela Universidade Federal do Ceará. Professor da Universidade Federal do Piauí. dados biográficos_biographic data 
Os trópicos são transportáveis, perfeitamente transportáveis e a saudade pertence ao velho vocabulário. Palmeiras, sóis, bananeiras, palmito, tudo isto é transportável.

$E$, se não for, a gente mesmo se transporta em imagem simultânea.

JORGE MAUTNER

\section{Introdução}

Em 1999, a publicação de dois textos reascendia um debate e mostrava que, se não havia algo de novo no front, velhos ressentimentos continuavam habitando as discussões sobre a cultura brasileira. Esses textos, publicados no jornal Folha de S. Paulo, colocavam em cena uma antiga disputa que ora havia oposto, historicamente, o Movimento Armorial do dramaturgo, romancista e professor de estética Ariano Suassuna ${ }^{1}$ e a Tropicália, para a qual o compositor Caetano Veloso havia, dois anos antes, com a publicação de sua Verdade tropical, assumido definitivamente a autoria. $\mathrm{Na}$ esteira das discussões que vinham sendo levantadas nesse final de século, quando o nomeado "movimento tropicalista" comemorava os trinta anos de seu acontecimento, Ariano, no artigo Dostoiévski e o mal, retomava as discussões que ora constituíam as divergências e ressentimentos entre uma e outra visão de Brasil. Para ele, em tom provocativo, o refrão da canção É proibido proibir, lançada por Caetano em 1968, auge das acontecências tropicalistas, dava a ler o argumento ateísta do movimento: se "é proibido proibir", tudo seria permitido, tal como colocaria a

\footnotetext{
1 Ariano Vilar Suassuna ficou reconhecido por sua produção dramatúrgica, especialmente pela publicação de Auto da Compadecida, escrita em 1955 e posteriormente adaptado para a televisão e o cinema, bem como pelo Romance d'A Pedra do Reino e o Príncipe do Sangue do Vai-e-Volta, publicado em 1971, e, posteriormente, adaptado para a televisão. A partir da produção artística, sob a forma de teatro e romance, bem como de sua tese de livre-docência $A$ onça castanha e a Ilha Brasil: reflexões sobre a cultura brasileira, defendida em 1976, estabeleceu as bases intelectuais do que ficaria conhecido como Movimento Armorial, caracterizado pela sua valorização de uma arte erudita, pautada nos valores da cultura nordestina, na forma de literatura, cinema, xilogravura, música, heráldica, etc. Professor de Estética, desenvolveu com alunos tais como Celso Marconi e Jomard Muniz de Britto diversos projetos culturais. No final da década de 1960, Marconi e Jomard envolvem-se em uma polêmica com Ariano na imprensa pernambucana, com artigos publicados no Jornal do Commercio e no Diário de Pernambuco, todos no ano de 1968, relativa à adesão dos dois ex-alunos do Auto da Compadecida, naquele momento, com o emergente "movimento tropicalista" (Cf. BEZERRA, 2009; CASTELO BRANCO, 2007; OLIVEIRA e BEZERRA, 2012).
}

célebre frase do personagem Ivan Karamazov, no clássico livro Os irmãos Karamazov do escritor russo Fiodor Dostoiévski. Se Deus não existisse, tudo seria permitido, insinuava Ariano, opondo a essa reflexão sua própria impressão sobre o mundo e a cultura. Para ele, ao contrário do que dizia enxergar nos "arroubos juvenis" da Tropicália, não se poderia nem deveria "desvencilhar-se de Deus", lançando, pois a lição: "Vejo que nem tudo é permitido, então Deus existe" (SUASSUNA, 1999).

A remessa de Ariano a Caetano parecia tratar-se de uma discussão de cunho ontológico, parecendo estar amparada no existencialismo sartreano ${ }^{2}$, compondo-se de um debate moral. A tomar pela personalidade polemista de seu principal interlocutor, o texto, certamente, se desdobraria em um contraditório. Em resposta, o compositor baiano escreveria o artigo Dostoiévski, Ariano e a pernambucália, onde defenderia que a opinião de Ariano incorria em "um ataque insidioso contra a razão e a lógica" (VELOSO, 1999). Sua defesa de uma moral cristã e o atrelamento desta a uma expressão da música tropicalista pareceria, aos olhos do autor da Verdade tropical, a expressão de uma não declarada antipatia de Ariano pela Tropicália, a qual, segundo ele, não seria recíproca. Em tom igualmente provocativo, Caetano Veloso toca no ponto que considera central no debate. Não seria a questão de cunho moral, mas sim a busca pouco disfarçada de Ariano por uma cultura eminentemente regional, pela qual esgrimia com toda e qualquer atitude que ampliasse os horizontes do Brasil. Devolve a provocação, especialmente quando insinua que a discussão levantada pelo autor do Romance d'A Pedra do Reino incidia, principalmente, nas tensões existentes no interior do próprio debate cultural pernambucano:

\begin{abstract}
A frase "É proibido proibir" é uma deliberada transgressão das leis da lógica que, com sua carga de humor e poesia, não atrapalha os verdadeiros amantes da razão. O raciocínio de Ariano é um ataque insidioso contra a razão e a lógica.

Imagino a cena do debate no Recife. O tropicalista pernambucano (talvez um pupilo do meu muito querido Jomard Muniz de Britto?) dizendo a Ariano que uma "ética do prazer" fundamenta a frase "É proibido proibir", e ele vindo com aquela história do
\end{abstract}

\footnotetext{
2 O filósofo francês Jean-Paul Sartre, em sua obra $O$ existencialismo é um humanismo, tornou-se, provavelmente, o inaugurador de um equívoco interpretativo da reflexão de Dostoiévski, reduzindo a ideia à sua essência, formatando, a partir daí, uma discussão de cunho ético e moral (SARTRE, 1973).
} 
sujeito que sai atirando em travestis e homossexuais e do tropicalista impedido de proibir essa matança. Quando se terá dado tal debate? Em 1968? Em 1986? Em 1995? (VELOSO, 1999).

É necessário perceber que ambos os textos se localizam em um momento histórico em que os embates culturais eram mais uma vez acionados diante da comemoração dos 30 anos do chamado movimento tropicalista. Esse momento arredondaria um sem número de discussões sobre a cultura, tão caras em momentos anteriores, que seriam expressas em produções artísticas, ensaios e trabalhos acadêmicos. Aparentemente, tanto às iniciativas que partiam das esquerdas organizadas quanto ao grupo do nomeado movimento tropicalista, ou mesmo com relação ao armorialismo de Suassuna, ganhavam espaço em uma ampla produção historiográfica que visa não apenas compreender seu lugar em uma época, mas também propor olhares mediados pelas vivências de certos sujeitos - então no âmbito da academia - a respeito do que se passara no miolo dos grupos-núcleo produtores de arte e cultura do Brasil do período. O objetivo deste artigo é, nesse sentido, analisar as diferentes produções discursivas que, entre as décadas de 1980 e 2010, buscaram produzir sentido à cultura brasileira, observando as tentativas sistemáticas de colocar-se enquanto lugares de saber e poder sobre essa cultura, bem como, em diversos casos, aparecendo enquanto linhas de fuga às tentativas sistemáticas de canonização da cultura brasileira, propondo.

\section{Tropicália, armorialismo e engajamento: diferentes caminhos da cultura brasileira}

Tidos hoje como clássicos, o trabalho de Heloísa Buarque de Holanda, o de Marcelo Ridenti e o de Maria Thereza Didier apontam caminhos para se pensar os debates e embates promovidos entre as artes ditas "revolucionárias", por seus vínculos de esquerda, seja entre si, seja estabelecendo-o com o que Holanda chamaria, já na primeira edição de seu Impressões de viagem, em 1979, de surto tropicalista da virada da década de 1960 para a década de 1970. Por sua vez, publicado em 2000, o trabalho de Marcelo Ridenti expressa o teor revolucionário que atravessaria toda a sua obra sociológica até então. Estudioso do chamado "fantasma da revolução brasileira", Ridenti redirecionava seu olhar sem perder seu foco. O que antes se encaminhava para a constituição da esquerda brasileira no âmbito dos partidos políticos e das agremiações estudantis se voltava, em seu Em busca do povo brasileiro, para o amplo debate que envolvia grupos juvenis vinculados às artes. O livro, uma espécie de inventário analítico do que se havia produzido no âmbito cultural, constituía um lugar de fala de um sujeito que outrora se envolvera nas atividades políticas e culturais do Brasil em tempos de regime civil-militar ${ }^{3}$. Para ele, em claro direcionamento político de seu texto, a cultura brasileira esteve, no período da ditadura civilmilitar, a serviço da resistência e das esquerdas, que se organizavam também nessa dimensão como forma de conquistar espaço e dizer o Brasil sob sua ótica. Por fim, mais direcionado aos debates localizados no espaço pernambucano, o trabalho de Didier, em forma de tese de doutorado, se trata de uma desconstrução do dito Movimento Armorial, visto por ela como uma iniciativa que, propondo-se uma inovação no olhar sobre a cultura brasileira, guardava relação com apoios políticos e motivações de cristalização do Nordeste como espaço de tradição, de forma a evitar que este espaço do Brasil ganhasse dimensões que extrapolassem suas fronteiras geográficas, promovendo, para isso, a invenção de um território imaginoso (DIDIER, 2000).

Mais do que produções acadêmicas que lançam sentidos a acontecimentos de uma época, esses textos dão embasamento para os próprios sujeitos que, nesse âmbito temático, buscaram, do lugar de produtores e divulgadores de cultura, instaurar um local para o Brasil e para a cultura brasileira. Tomando tanto as produções que partiam da chamada esquerda organizada, em especial o CPC, quanto o dito movimento tropicalista, ou mesmo a figura emblematizada de Glauber Rocha, em torno do qual construiu-se uma espécie de síntese do cinema brasileiro moderno, ou, por fim, o próprio Ariano Suassuna e seus contemporâneos, é possível perceber que eles se tratam de repertórios interpretativos, tendo como objetivos mais profundos o de "demarcar o rol de possibilidades de construções discursivas" a respeito dos sujeitos e práticas em questão (SPINK e MEDRADO, 1999, p. 47). Não são incomuns, a partir dos anos 1980 essas tentativas de produzir um revisionismo, de lançar interpretações ou de configurar sentidos a respeito de certas produções

\footnotetext{
3 Utilizo nesse trabalho a designação ditadura civil-militar ou regime civil-militar em consonância com a produção de Daniel Aarão Reis Filho, na medida em que compreendo ter sido o regime de exceção que vigorou no Brasil entre 1964 e 1985 demarcado pela participação não apenas de uma ampla parcela dos militares quanto também de um número expressivo de sujeitos da sociedade civil (REIS FILHO, 2014).
} 
artísticas brasileiras, na intenção de lhes empoderar, dar legitimação à sua maneira de falar do Brasil. Essa perspectiva, de demarcar o rol de possibilidades a respeito do qual algo será dito historicamente, é percebido no texto que Holanda escreveria em 1983, publicando-o em duas partes no Jornal do Brasil. Poetas rendem chefes de redação seria, portanto, uma forma, posterior à publicação de Impressões de viagem, com a qual essa autora reafirmaria os sentidos da Tropicália e sua vontade de verdade sobre um período político e cultural do Brasil:

Não seria exagero afirmar que, hoje, a coluna Geléia geral tornou-se material indispensável para o estudo e para se ter o feeling da polêmica história da cultura no início da década de 70. Mas antes de demonstrar a importância do "conteúdo" que circulou, ou da frente de resistência que foi Geléia geral, quero falar de seus aspectos propriamente formais enquanto prática jornalística experimental. Ideólogo do Tropicalismo [...], Torquato traduz na escrita do jornal e no formato da coluna diária a estética do fragmento que norteia o discurso tropicalista. "Sínteses. Painéis. Afrescos Reportagens. Sínteses. Poesia. Posições. Planos gerais. O close up é uma questão de amor. Amor." Apostando em Oswald de Andrade quando disse "no jornal anda todo o presente", Torquato descobre esse presente maior do que o fato e trabalha na composição de um mural em mosaico, quebrado, fragmentado, [suspeito] (HOLANDA, 1983, s/p.).

Armada, ela própria, de um discurso que buscava celebrar "o projeto existencial e político com que o Tropicalismo enfrentou aqueles tempos de espaçonaves e guerrilhas" (HOLANDA, 1983, s/p.), Heloísa Buarque de Holanda promove um revisionismo no qual resguarda à Tropicália - ou, de maneira mais cristalizada, ao movimento tropicalista - uma ética e uma estética. Mais do que isso, um projeto estético, político e ideológico para o Brasil. Para isso, toma o poeta e letrista piauiense Torquato Pereira de Araújo Neto, entendido, via de regra, como uma figura marginalizada na história "oficial" do movimento, e, paradoxalmente, romantizada pela posterior produção acadêmica, a quem ela própria exalta, lhe dotando da alcunha de "ideólogo do Tropicalismo", e tradutor de uma estética do fragmento na imprensa brasileira da época em que circulava, no jornal carioca Última Hora, a coluna Geléia geral. A despeito da possibilidade de considerá-lo um mito cultural, forjado nas práticas discursivas produzidas no Piauí, terra natal do poeta, e mesmo fora dela, não me parece, portanto, inocente a atitude de Hollanda, em exaltar Torquato e a dita coluna nesse espaço, assim como não me parecem inocentes outras iniciativas posteriores de afirmação de mais uma tentativa midiática de refletir sobre a cultura brasileira.

O tom utilizado por Heloísa Buarque de Holanda, em 1983, bastante próximo do que, ainda no final dos anos 1970, havia feito Celso Favaretto, na publicação de seu Tropicália: alegoria, alegria, faz ainda mais sentido se pensarmos que outros discursos a respeito dos acontecimentos culturais do Brasil emergiriam, ainda com mais força, no final da década de 1990. Independente de seus posicionamentos, há algo em comum nessa historiografia, que entende a Tropicália, ou mesmo o posterior movimento tropicalista, como desenvolvendo uma efetiva preocupação com a linguagem, capazes de pensar a existência de uma multiplicidade de significados nacionais: "de um Brasil firme, por exemplo, dormindo entre cascatas, palmeiras, araçás e bananeiras ao canto da juriti [...] a um Brasil perigosamente solto no espaço, misturando-se a gin-tônicas, coca-colas e milk-shakes" (CASTELO BRANCO, 2007, p. 78).

Naquele momento histórico, especificamente nos anos 1996 a 1998, se tornavam recorrentes notícias, matérias de jornal, programas de televisão, entrevistas e tantos outros eventos midiáticos que comemoravam os 30 anos da Tropicália, inserindo-a no interior de tantas outras iniciatias e movimentos da música popular brasileira. Em paralelo à produção acadêmica já citada, emergiam textos que partiam dos próprios artistas e intelectuais que participaram dos acontecimentos da época. Obras revisionistas, tais como Tropicalista luta lenta, de Tom Zé, Noites tropicais, de Nelson Motta, ou Chega de saudade, de Ruy Castro, fermentavam um debate que já era feito pelo crítico cultural Carlos Calado, que, em seu Tropicália: a história de uma revolução musical, buscava evidenciar o "movimento tropicalista" como sendo algo centrado nas figuras de Caetano Veloso e Gilberto Gil, sendo as demais produções futuras, encabeçadas por artistas como Arnaldo Antunes, Carlinhos Brown e Kleiton e Kledir, herdeiras do Tropicalismo (CALADO, 1997). Em sentido semelhante, figuras como Gal Costa e Caetano Veloso demonstravam seu esforço para agregar em torno de si os múltiplos significados que se construíam em torno da Tropicália, e, em medida mais ampla, das dizibilidades a respeito do Brasil nas décadas de 1960 e 1970. Nesse mesmo contexto, em janeiro de 1998, jornais noticiavam que a Tropicália teria um bloco de 
Carnaval na Bahia (O DIA, 1998, p. 21), e, em maio daquele mesmo ano, artistas como Belchior e Cássia Eller, dentre outros, participariam da coletânea musical Canções do Divino Mestre, conceituado pela imprensa da época como uma produção "pós-tropicalista" (O DIA, 1997, p. 23).

Tanto no texto de Holanda quanto nos múltiplos acontecimentos que se processariam na década de 1990 é possível perceber que estes sujeitos sentiam uma necessidade premente em remeter à continuidade. $\mathrm{O}$ texto de Holanda, por exemplo, se esforçar em pinçar, no fragmento que toma de Torquato Neto aquilo que nas suas maneiras de enxergar, no momento histórico que pinça, a cultura brasileira, uma retomada de visões modernistas. Se Heloísa Buarque de Holanda vê remessas de Torquato a Oswald de Andrade, quando esse diz "no jornal ando todo o presente", ao falar da Tropicália nos anos 1990, ao celebrá-la como uma tentativa de dizer o Brasil sob a ótica de uma antropofagia cultural, um outro tanto conjunto de sujeitos promovia uma reapropriação dos discursos de outrora, dando-lhes vitória.

O caso a ser pensado, nesse trabalho, é que a Tropicália, tal como defendera Edwar de Alencar Castelo Branco, não se tratou de um movimento cultural organizado a priori. Sua conformação se deveu, muito mais, a um conjunto descontínuo de acontecimentos, na história da cultura brasileira recente, presente em iniciativas artísticas de muitas naturezas (CASTELO BRANCO, 2005). No entanto, o peso das análises produzidas a posteriori se impõem às tentativas, que se desenrolaram a contrapelo, de desconstruir, arqueologicamente, os discursos de vitória sobre o chamado movimento tropicalista como uma tentativa marginal de dizer o Brasil. No entanto, aquilo que poderia ser visto, em meados dos anos 1960, como iniciativas de ruptura e fragmentação com as propostas estéticas e políticas de um tempo - a bossa nova, a arte engajada, a Jovem Guarda - ganhava, poucos anos depois, forma de um movimento organizado, grandioso, com amplo espaço na mídia e defensores empedernidos. Não é estranho perceber, mesmo nas linhas que se propõem mais sóbrias sobre o assunto, como aquelas escritas por Frederico Coelho, autor da tese Eu, brasileiro, confesso minha culpa e meu pecado, resquícios de uma Tropicália que se deseja vencedora, armada de amplo aparato ideológico e evidentemente organizada (COELHO, 2010), tal como fala a canção homônima de Caetano Veloso, que, assim como a coluna Geléia geral, foi voluntariamente indicada como um dos manifestos do dito "movimento".
Voluntariamente nomeada como um movimento plural, antropofágico e demarcado pela estética do deboche, a Tropicálianão seria, em suas intenções, muito diferentes de outras tentativas de afirmação da cultura brasileira. Dizia-se herdeira de Oswald de Andrade e de algumas - muitas - propostas do modernismo paulista. Assim como a luso-tropicologia proposta pelo sociólogo Gilberto Freyre, buscava dar forma a uma cultura brasileira híbrida, e, se não harmoniosa, certamente celebradora da pluralidade. Tal como o armorialismo de Ariano Suassuna, encontrou na mídia espaço de divulgação de suas ideias. Exemplo disso seria o amplo amparo de artistas como Caetano Veloso, Gilberto Gil, Gal Costa e Maria Bethânia em programas de televisão, a aliança destes com grandes gravadoras, tais como a Polygram, e a evidente tendência de serem os detentores das verdades presentes nos discursos de documentários sobre a época, tais como Uma Noite em 67, de Renato Terra e Ricardo Cali (2010), e Tropicália, de Marcelo Machado (2012). A grande preocupação em ambos em muito se assemelha àquela da produção memoralística e historiográfica que se deu desde os anos 1970: queria-se demarcar um lugar de poder sobre uma época, um lugar hegemônico e patrimonializado, que deveria ser reverenciado pelas gerações futuras.

Pensado como parte de uma discussão que vinha sendo retomada, as questões que medeiam a querela entre Ariano Suassuna e Caetano Veloso dizem respeito, portanto, a um lugar próprio na história do Brasil. Suas vivências, no entorno das décadas de 1960 e 1970, instituíam os lugares que ocupavam nos debates intelectuais dos anos 1990, nos quais se punham à prova seus posicionamentos e suas contradições. A invocação do folclórico e de uma cristianização da cultura brasileira por Ariano Suassuna, insinuando o maniqueísmo - a busca por demarcar claramente a existência do bem e do mal - aparecem, portanto, como a motivação central da provocação lançada a Caetano Veloso, contrapondo-se, dessa maneira, à teogonia dos baianos. A "resposta tropicalista" continuaria, na mesma esteira filosófica lançada por seu provocador:

Se digo que sua verdadeira discussão seria aquela, é por causa do exemplo escolhido por Ariano. Mas igualmente verdadeiro e seu seria discutir com Ariano se a afirmação cultural do Brasil reduz-se mesmo ao programa algo kitsch de estilização bairrista da arte folclórica do Nordeste como forma de restauração do medievo ibérico. Porque o verdadeiro opositor do dogma armorial é o natural rigor da bossa nova. 
Tom Zé está certo. O valor do tropicalismo se resume a sua coragem de gritar que não podemos fugir às responsabilidades criadas por João Gilberto e Tom Jobim. Ariano fala com frequência contra o tropicalismo, mas suas poucas palavras de desprezo pela arte de Jobim foram mais eloquentes.

[...]

E não porque Ariano creia em Deus e eu não creia - que João Gilberto crê talvez com mais firmeza -, mas porque o que vislumbro por trás da hipótese de o armorial (e não a bossa nova) ser o dominante ou hegemônico é um Brasil onde ódios irracionais como esse contra travestis sejam a norma e a lei oficiais. Quando grito, cada vez que se arma uma celebração retrospectiva do tropicalismo, "a luta continua", é isto que estou querendo dizer (VELOSO, 1999).

A querela cultural, travestida de debate filosófico, entre Ariano Suassuna e Caetano Veloso, traz consigo um bom pretexto para algumas das discussões possíveis a respeito da constituição de uma linha evolutiva da cultura brasileira, que se precipitariam nos momentos posteriores aos filmes de Jomard Muniz de Britto nos anos 1970. O debate erudito, ora travado por armorialistas e tropicalistas, vaza as fronteiras da cultura brasileira para perscrutar, além de si mesmos, alguns argumentos possíveis, nos quais consolidariam suas muralhas conceituais. Dessa maneira, a reflexão feita por Dostoiévski, através de seu personagem, Ivan Karamazov, ora tomada por Ariano, incide em outras reflexões possíveis, transformando-se em uma metáfora. Deus, a figura sagrada, poderia ser lida como signos que representam as visões canonizadas, sacralizadas, de Brasil. "Se Deus não existisse, tudo seria permitido", diria o romancista russo, pelos lábios de Ivan. No tempo-espaço em que se discute um lugar para essa cultura, no entanto, é possível perceber que o posicionamento do dramaturgo de Taperoá é favorável à existência de Deus, e, portanto, de limites aos significados do Brasil. A metáfora de Dostoiévski se aplica, nesse sentido, às possibilidades oferecidas aos vislumbres de um país, uma vez que se as tentativas se delimitação da ideia de cultura brasileira - salvaguardadas, deificadas e cristalizadas por instrumentos políticos, ideológicos e institucionais - não existissem, todo e qualquer delírio sobre esta referida cultura seria permitido.

A partir dessa análise, cabe notar que a tentativa de nomeação e demarcação de um local para a cultura configurou, em uma duração que extrapolava mesmo os momentos em que tais eventos eram mais evidentes, uma relação identitária de tensões e aproximações. $\mathrm{Na}$ medida em que se pode compreender a inexistência de um eu idêntico a si mesmo, particularizado, iluminista e único, é igualmente possível pensar a necessidade de vislumbrar a identidade como algo fluido, móvel, configurado na multiplicidade de matrizes que ora compõem os sujeitos (HALL, 2014). Esses sujeitos eram e são profundamente diversos, e igualmente diversas eram as suas expressões. Provavelmente, no entanto, algo todos eles tinham em comum: a necessidade de produzir, discursivamente, um Brasil dos sonhos. Mas que sonhos, afinal, traziam consigo? É provável que a colocação de Castelo Branco, a pretexto do processo de invenção discursiva da Tropicália, que ora vinha sendo expressa na figura de Caetano Veloso, nos ajude a refletir a respeito:

[...] Está claro - creio - que um Brasil dos sonhos é algo muito relativo em uma sociedade, como a nossa, com grande desigualdade social, se este for o critério, mas também com múltiplas referências artísticas e culturais, o que também torna difícil a unanimidade em torno de um sonho. Penso então que apenas porque aprendemos a ver o sujeito Caetano como o nosso guia, na verdade tropical - isto ainda antes do lançamento do livro -, desaprendemos a ver outros sujeitos e manifestações que igualmente propunham um sonho de Brasil. [...] (CASTELO BRANCO, 2005, p. 106-107).

Penso, pois, que nem Ariano nem Caetano embora ambos estabelecessem tal coisa como devir -, tampouco Gilberto Freyre, Florestan Fernandes, ou quaisquer outros que, historicamente, tenham isso buscado, acumulavam em torno de si a verdade tropical, ou seja, a única maneira de dizer e pensar o Brasil. Suas visões, a pretexto de demarcar um lugar para a contemporaneidade brasileira, tinham como objetivo maior manter vivo um debate que continuaria ainda mais vivo nos anos que viriam a seguir. A exemplo disso, em 2003, o intelectual multimidiático Rogério Duarte publicava Tropicaos, compilação de um conjunto de textos seus, nos quais conformava uma espécie de inventário da Tropicália dos anos 1960, vista, evidentemente, a seu modo. Inserida no âmbito de uma série de outras leituras que remetiam aos acontecimentos do período, a publicação trazia como seu diferencial o fato de perceber, de maneira provocativa, a existência de pelo menos três dimensões de Tropicália: a dos tropicalistas mortos (Hélio Oiticica e Torquato Neto), 
a dos tropicalistas ricos (Caetano Veloso e Gilberto Gil) e, por fim, o verdadeiro tropicalismo, aquele que, em sua visão, jamais teria acontecido, uma vez que fora reprimida pela ditadura. Em suas próprias palavras, potencialmente autobiográficas, o Brasil que emergiria dessa Tropicália era um Brasil revolucionário, cuja potência existiria no mito da sua transformação em uma nação grandiosa e eloquente. Para ele, as respostas estariam justamente na "manifestação dessa audácia brasileira": a verdadeira vida ainda estaria por ser inventada, bem como o "verdadeiro tropicalismo" (DUARTE, 2003, p. 149-150).

Corroborando com o revisionismo potencialmente crítico de Rogério Duarte, em 2012, o compositor Tom Zé, também considerado uma das figuras proeminentes, porém pouco evidenciadas, da Tropicália, lançaria não um livro, mas um álbum sonoro, onde igualmente produziria uma revisão crítica dos anos 1960 e 1970. Tropicália lixo lógico já nascia, desde seu título, como um instrumento que pretendia submeter o movimento tropicalista, tal como essa havia se constituído, ao formigamento constitutivo de seus começos. Em cada uma de suas canções - tais como Tropicalea Jacta Est, que grava com a cantora Mallu Magalhães - Tom Zé, ainda que revestido de um possível ideal conciliatório, procura explodir os alicerces nos quais se basearam esse movimento cultural, alterando sua imagem para a de um antimovimento. Uma das letras com maior potencial detonador é a de Apocalipsom A (O Palco no Fim do Começo), gravada em dueto com o rapper Emicida, no qual enxerga a Tropicália não como uma unidade, mas como uma mistura difusa de signos, imagens, textos e personagens, nascendo como um jorro de vômito, uma mistura nada fina, mal aceita e mal digerida entre "Deus e o Diabo", "fé e conhecimento", "o saber de Aristóteles com a cultura do mouro", "Apolo, Macunaíma, Diana, Vênus, Urânia, Chiquinha Gonzaga e Bethânia”:

\footnotetext{
Personae iures alieni

Diabo e Deus numa sala

Firmou-se acordo solene

De unir em casamento

A fé e o conhecimento

Casou-se com muita gala

O saber de Aristóteles

Com a cultura do mouro

Pra ter num só filhote

O duplicado tesouro
}

\author{
E toda casta divina \\ Estava lá reunida \\ Apolo e Macunaíma \\ Diana, Vênus, Urânia \\ Chiquinha Gonzaga Bethânia
}

O diabo ali presente

de todo banco gerente

(Conforme o cabra da peste

chamado Bertold Bretch)

Tinha comida e regalo

tinha ladrão de cavalo

pai de santo e afetado

Padre, puta e delegado

$\mathrm{E}$ as meninas meu rapaz

Cresceu depressa demais

anda presa na soltura

circula na quadratura

e o sossego ela não deixa em paz

Cada dia mais esperta

A molecada desconcerta

No senso que ela retalha

Não há quem bote cangalha

se você faz represália

ela não passa a mão na genitália

esfrega na sua cara

Mas...

Onde a cultura vige

e o conhecimento exige

recita noblesse oblige

com veludo na laringe

castiça cantarolando

Quod era demonstrandum

e recebida na sala

Se trata por tropicália (ZÉ, 2012)

Como se pode perceber, exemplificados no trecho de ensaio e na canção, as afirmações de Rogério Duarte e Tom Zé frutificam quando pensamos no conjunto de visionários que, entre as décadas de 1960 e 1980, lançaram olhares sobre o Brasil profundo, desinventando-o e invertendo o polo de sua realidade. Tomando os escritos desses personagens, analisados anteriormente, o Brasil emergiria do potencial criador do caos, de uma visão de sua tropicalidade que ainda não havia sido fabricada, encontrando-se do lado de 
fora dos espaços institucionais de saber e poder que mediam a relação entre o conhecimento (ou uma ideia de cultura) e o povo. Esses espaços, responsáveis pela elaboração de uma produção discursiva empoderada, potencializada como verdade, haviam construído dizeres e fazeres que, impedindo a passagem de outros, reificavam seus sujeitos e suas próprias narrativas.Por todos esses motivos, a economia simbólica contida nos escritos de Rogério Duarte e na musicalidade de Tom Zé dão vazão ao fato de que essa pretensa cultura brasileira - dita, afirmada, inventada e, em larga medida, imposta como padrão estético, político e ideológico para o Brasil - não daria conta de necessidade de entrever as questões profundas de um país cuja potência deveria ser historicizada.

\section{Contra-dicções da cultura brasileira: a "psicanálise selvagem" de Jomard Muniz de Britto}

Essas considerações permitem que entrevejamos um sujeito perdido entre as deserções de uma linguagem entre a qual cambiava. Tratava-se do filósofo, professor universitário, produtor de filmes experimentais e ativista cultural pernambucano Jomard Muniz de Britto. Personagem que percorreu, entre os anos 1960 e os dias que se aproximavam, um caminho nada ortodoxo, em se tratando de formação intelectual e de militância cultural, Jomard atuou como professor universitário na Universidade do Recife, sendo compulsoriamente aposentado quando do golpe civil-militar de 1964. Naquele mesmo ano, publicou Contradições do homem brasileiro, texto que refletia sua atuação na militância educacional de esquerda, próximo de figuras do cenário intelectual perseguido pela ditadura, tais como o educador Paulo Freire. Em 1966, publicou Do Modernismo à Bossa Nova, esforço de constituição de uma filosofia da cultura brasileira, que seria acompanhada por sua aproximação com os ideais tropicalistas no final dos anos 1960, com a passagem de Gilberto Gil pelo Recife e com o lançamento dos manifestos culturais Por que somos e não somos tropicalistas e Inventários de nosso feudalismo cultural, ambos publicados em 1968, no Jornal do Commercio. Tal atuação produziria tensões entre Jomard e seu antigo mestre, Ariano Suassuna, cujas rusgas resultaram na produção de filmes experimentais, feitos em formato super- 8 , tais como O Palhaço Degolado, no qual critica as tentativas de canonização da cultura brasileira, apontando seus potenciais ressentimentos quanto a figuras tais como Gilberto Freyre e o próprio Ariano. Como é possível perceber, entre a vivência universitária do início dos anos 1960 e a experiência tropicalista do final dessa década, entre essa e a guerrilha superoitista dos anos 1970, e, mais adiante, entre esse momento de sua vida intelectual e o que viria a seguir, temos a constituição de muitos Jomares, de tantos sujeitos que efluem, que lutam entre si, que se enfrentam, que morrem e nascem outro.

No final dos anos 1970 e início dos anos 1980, período em que era observada a ainda tímida abertura do regime político civil-militar do Brasil, Jomard Muniz de Britto vivencia novamente a experiência de docente universitário, voltando a atuar como professor da Universidade Federal da Paraíba. Na mesma época, passa a atuar na Fundação de Cultura, órgão então vinculado à prefeitura da cidade do Recife. No entanto, em 1987, sob a gestão de Jarbas Vasconcelos na administração da cidade, Jomard é tomado de assalto com a notícia de sua demissão do órgão. Aparentemente surpreso com a notícia, concede, em 03 de maio daquele ano, uma entrevista ao Jornal do Commercio, onde, em sua conversa com o jornalista Marcelo Pereira, atribui sua demissão à permanência de valores conservadores nas políticas culturais pernambucanas:

[...] A psicanálise que faço é que a cultura pernambucana continua sendo uma cultura muito enfeudada. São grupos, micropoderes, que lutam até o fim dentro das suas fronteiras. $\mathrm{O}$ desejo nosso sepre foi alargar essas fronteiras. Eu disse em uma entrevista que inclusive desagradou algumas pessoas, uma coisa que achou boa repetir: me perguntaram o que eu achava da cultura pernambucana, quando o governador estava assumindo, e eu dizia que o governador falava muito do ponto de vista que "a cultura é do povo". Mas para chegar a essa captação, a essa recepção da cultura legitimamente do povo, você tem que passar por muitas mediações, que são os grupos culturais, organizadores da cultura, os presidentes das fundações (BRITTO, 2013, p. 124).

Não cabe a mim especular sobre os motivos que levaram, de fato, Jomard Muniz de Britto a ser demitido da Fundação de Cultura. Entretanto, cabem algumas considerações que, a partir de sua fala, ficam implícitas sobre suas opiniões, ainda permanentes, sobre a condução das políticas culturais em Pernambuco. Para ele, permanecia o chamado "feudalismo cultural", averso à modernidade; permanecia o jogo de poder 
que, no âmbito da cultura, fazia valer os dispositivos de disciplinação das práticas culturais, como formas de enquadrar as políticas de valorização de uma certa cultura brasileira, nordestina e permabucana no interior de uma função estratégica dominante. E, diante dessas permanências, se instaurava, agora de maneira definitiva, o espectro do ressentimento, o apodrecimento de uma linguagem já gangrenada, que, se outrora gerara guerra, agora o conome, confirmando que sua lut contra gigantes moinhos de vento parecia, mais do que nunca, tal como afirmara, em 1978, em $O$ Palhaço Degolado, uma luta vã.

Nesse sentido, as esgrimas de Jomard Muniz de Britto, que, a certa altura, havia se enxergado como um exército de um homem só, apareciam como vertentes que escorriam pelos entremeios da cultura canônica, espertando lugares de fala outros, e estabelecendo contrapontos à sua linha evolutiva. Na medida em que seria considerado, inclusive pela própria imprensa que o buscou entrevistar e enquadrar, como último dândi, Jomard passaria a não mais propor uma tentativa de explicá-la, ainda que de maneira esgrimística em relação às concepções mais aceitas. Procuraria, ao contrário, fugir dela, romper com ela, escapar pelas brechas de suas possibilidades. Suas entrevistas mais recentes são potentes em denotar um personagem que em nenhum momento nega a si mesmo, mas que, no ato de aceitar as suas contradições, desliza por entre os dedos dos enquadramentos, das tentativas de captura e de canonização de suas ideias, potencialmente subcanonizadas. Tal maneira de se posicionar encontra lugar, por exemplo, na entrevista concedida ao jornalista Carlos Adriano, na revista eletrônica Trópico, em 2005. Nesta, em uma das partes estrategicamente silenciadas em sua posterior publicação no volume Encontros, organizado por Sergio Cohn, ao ser indagado sobre suas polêmicas com Ariano Suassuna, sua amizade com Glauber Rocha, ou mesmo sobre movimentações culturais mais recentes, como o mangue beat, Jomard parece não se deixar tomar, sempre usando da linguagem como um instrumento de fuga, atentando contra a palavra, usando e abusando dos sofismas, fazendo da linguagem uma forma de promover o enigma:

Quando A.S. (amado sofista?) defende como fundamento do Armorial "uma arte erudita brasileira a partir das raízes populares", seu projeto estético-ideológico está bem definido. Paradigma transdogmático. De Euclides da Cunha a Mário de Andrade, ultra(re)passando o integralismo de Plínio Salgado. Ou não, como ainda repetiriam os indóceis bárbaros.
De qualquer entre-lugar do planeta manguedendê-olodum-aparelhagem. Ariano Suassuna, em termômetro global do "conteúdo Brasil", representa a vitória ou hegemonia do nacionalpopular: tanto do ponto de vista fervoroso da esquerda católica e do catolicismo sertanejo (sic) como da mais-valia do riso globalizado. Pela intervenção audiovisual de Guel Arraes chegamos ao clímax misericordioso do Neon-Armorialismo. O "Auto da Compadecida" enfrentando não apenas as guitarras elétricas da arqueologia tropicalista, mas também desmascarando todas as terras em transe e bandidos da luz vermelha. Em nome do Pai e do Brasil Profundo. Muito além e aquém dos "dogmas mentais" e metaleiros. Muito pelo contrário: transpondo e transbordando as teorias da complexidade. Pós-Freud. Pós-Marx. Pós-Morin. Ariano par-lui-même.

[...]

Diante do perfil tão multifacetado, como não continuar admirando e homenageando nosso gênio da nordestinidade? Da brasilidade? Do terceiromundismo? Do nacional-popular eternamente em berço esplêndido? (BRITTO, 2005).

O que é possível entrever dessa maneira de posicionar-se diante do Brasil adotada por esse Jomard Muniz de Britto, que parece, curiosamente, hoje, querer se desvencilhar do conflito com Ariano Suassuna, que outrora marcou suas vivências? O que, numa primeira e mais ingênua visada, poderia parecer uma tentativa de reconciliação, aponta para muito além das polêmicas que, no passado, os envolveram. Se tomarmos esse trecho de entrevista juntamente com os artigos publicados por Ariano Suassuna e Caetano Veloso nos anos 1999 - embora os dois artigos, ao contrário da entrevista, assumam a postura do debate frontal -, encontramos neles questões que mobilizaram artistas e intelectuais no passado, vivas e presentes. São elas que, hoje, ainda parecem entrelaçar não apenas Jomard aos seus antigos afetos e desafetos, mas também aos demais visionários de um Brasil profundo, que, numa dimensão temporal elasticizada, propuseram vislumbres da brasilidade. Podemos perceber, no trecho acima, que o tom aparentemente conciliatório de Jomard cai por terra diante da ironia que assume ao chamar Ariano Suassuna de "gênio da nordestinidade, da brasilidade, do terceiromundismo, do nacional-popular eternamente em berço esplêndido", ao celebrá-lo "em nome do Pai e do Brasil Profundo". 
A postura de escárnio, portanto, é uma permanência na visão de Brasil lançada por Jomard. A mesma postura que demarcou sua decepção com o Brasil, sua necessidade de vê-lo explodir em mil pedaços, dá forma ao sorriso recheado de ironia que este abre ante a denotação dessa ilha. Esses imprevisíveis significados que explodem a partir dos estilhaços chamuscados da carbonizada Ilha Brasil expressam a ruptura com a ideia tóxica de uma identidade fixa e a emergência de um ideal de subjetividades, de identidades flexíveis. Uma vez que pensamos a vontade de verdade como estando articulada a um poder do qual emanam os discursos (FOUCAULT, 1996), cabem pensar que suas falas intentaram interditar tantas outras, cujo desejo de falar terminou sendo calado ante as vozes vitoriosas. À margem da linha evolutiva que, rivalmente, cada um deles tentou nomear, perambulavam outros sujeitos e leituras sobre o Brasil. Convergindo com minha afirmativa, é possível ver pelas frestas o extrato de uma carta, endereçada do escritor paraibano Bráulio Tavares a Jomard Muniz de Britto em 8 de junho de 1984, publicado em Bordel, brasilírico, bordel, reunião de textos deste. O conteúdo da carta, enigmático e fragmentário, pode servir de pista para as discussões que pretendo fazer neste capítulo:

Jomard:

Literalmente soterrado sob laudas e laudas de Modernidade, não tenho outra alternativa senão pensar no assunto. Primeiro ponto: gostaria que fosse inventada uma palavra nova para falar no assunto sem que todo mundo começasse a pensar na Semana de 22. Segundo ponto: uma referência mais substancial seria o Tropicalismo, embora já seja também verbete de enciclopédias da Editora Abril: mas já é algo que envolve música popular \& cinema \& TV \& cultura-de-massas, portanto dá de goleada nessas outras modernidades antigas. Terceiro ponto: a Modernidade fluida, impalpável, ectoplásmica de H. Lefebvre (tô citando a partir das citações no teu artigo no "Correio") é uma coisa meio atonal, né não? Propor uma coisa com essa vagueza toda é garapa, se eu quisesse eu inventaria uma moda assim toda semana. Quarto ponto: se até Zé Guilherme Melquior, que nunca li, mas que não tenho vontade de ler, se permite inventar uma modernidade própria para consumo interno, então, ora que diabo, qualquer um pode inventar a sua. Eu também posso inventar uma minha, de repente batizo até de Silibrina, que pelo-sim-pelo-não é um nome carismático e que não tem no dicionário.
Porque de repente chega um cara e diz que moderno é tudo que mistura a casa-grande e a senzala (e eu perguntaria: e por que, em vez de Casa-grande, não se mistura Sócrates?). E vem outro e diz que moderno é o que mistura o primivitismo e a tecnologia, formiplac-e-céu-de-anil. E vem um terceiro e diz que moderno é o que mistura o LSD com o PMDB; e outro diz que não, que é misturar ideogramas chineses com video-games americanos, e por aí vai. Resultado: cada qual inventa sua receita de ser moderno - mas nenhum ainda disse nada do modelo do meu terno (BRITTO, 1992, p. 171).

Esse trecho pode ser tomado como um pretexto para observar as discussões sobre o Brasil e a cultura brasileira forjados ao longo das décadas anteriores, mas vívidos na época em questão. Se, por um lado, expressa uma necessidade de manter vivo um debate antigo - a indagação sobre que lugar ocupa a cultura na forjação de uma nação e de sua pretensa modernidade -, por outro, torna-se um exemplo potente de como a ideia do moderno, no interior dessa mesma cultura, ganha uma extensão fluida e profundamente problemática. Refletindo mais detidamente sobre esse texto, é possível perceber que nele é colocado em suspeição o conceito tradicional de modernidade, uma vez que seu autor, em tom irônico, polemiza o local que este ocuparia nas discussões sobre a cultura brasileira, bem como sua própria nomeação, sob a forma de uma linha traçada em forma de reta no sentido evolutivo. Assim como o famoso cachimbo do quadro de René Magritte nos denota uma relação entre a imagem e o seu significado, a ideia de modernidade se articula aos movimentos e textos que a ela fizeram reverência (FOUCAULT, 2014, p. 22), tal qual levanta Braulio Tavares: a Semana de Arte Moderna de 1922, a Tropicália e as reflexões do filósofo Henri Lefebvre. O resultado dessa reflexão parece ser uma tentativa rebelde de (re)nomeação de um conceito, que se desdobra a partir de muitas possibilidades, uma vez que "cada qual inventa sua receita de ser moderno": a casa-grande de Gilberto Freyre, o hibridismo tropicalista formiplac-e-céude-anil, a articulação entre os universos orientais e ocidentais. Nesse sentido, continua Tavares:

Porque eu vejo essa multiplicidade como uma coisa essencial para um trabalho criador. Alguns a sacrificaram em benefício de uma obra mais nítida, mais cortante, mais monobloco. Mas se existe algo que eu me atreva a chamar de Modernidade na minha língua, passa por aí. Não é um critério 
cronológico, não é um critério vanguardista ("Quem primeiro fêz isso foi Fulano de Tal"), não tem muito a ver com contestação em qualquer plano (estético, político, existencial), ou pelo menos não-o-temnecessariamente: tem a ver com o fato de permitir múltiplas leituras, uma vez que se trata de uma escritura múltipla. E essa multiplicidade, em grande números dos casos, é obtida através da mistura, que pra mim é a figura poética por excelência. Miami com Copacabana, chiclete com banana, Smetak com muzak, maracatu com Maracanã. [...] (BRITTO, 1992, p. 173).

A carta nos dá outras pistas e serve como importante ponto de partida. Cabe observar que nela fragmentase um olhar sobre o Brasil: não mais Pindorama, o país do futuro, ordenado por uma lógica de progresso, tal como desejavam os modernistas de São Paulo da década de 1920, tampouco o saudoso Brasil freyreano, onde ressonavam no mesmo compasso batuques negros e acordes portugueses. Também parecia ser um Brasil incomodado com as amarras de uma inventada Tropicália, que se tornara um objeto enlatado, capturado pelos instrumentos midiáticos. No interior de sua narrativa, pulula uma modernidade brasileira marcada pela bricolagem, a mistura fina que a delinearia seria modeladora de um Brasil que escorria pelos significados de palavras novas, ou pelo menos pouco utilizadas nas suas delimitações mais tradicionais.

\section{Considerações finais}

Seguindo esteira semelhante aos demais discursos levantados, as diferentes perspectivas apontadas por Bráulio Tavares, em torno da modernidade proposta para o Brasil, se apresentavam, ao mesmo tempo, como uma interpretação e um projeto político para o país. Se, por um lado, a atitude desse autor poderia denotar algum traço de narcisismo conceitual, é evidente em seu texto a necessidade de gestar palavras, ou, pelo menos, de perceber que nelas nada se encerra, mas que tudo pode se metamorfosear, ganhando outros tantos possíveis significados. Diferente dos sujeitos a quem, direta ou indiretamente, se refere, sua ideia de modernidade não se centra em uma linha evolutiva, tal como propuseram, anos atrás, intérpretes do Brasil como Gilberto Freyre ou Caetano Veloso, tampouco numa vertente políticoideológica, como apontara Florestan Fernandes e seus contemporâneos, muito menos em uma dimensão conceitual-estético-existencial, como, em linhas gerais ou específicas, propuseram figuras tais como os modernistas paulistanos de 1922 ou Ariano Suassuna em recortes mais recentes.

Dessa maneira, a cultura brasileira que emergiria entre tradições e dicções, tal como esforçaram-se em estabelecer os sujeitos que cito acima, habitaria, igualmente, um outro terreno, o das contra-dicções, menos falado porque menos desejado e potencial incômodo, no interior do qual haveriam de explodir suas principais linhas de fuga. Em suma, é no interior dessas contra-dicções que explodem uma gama de possibilidades-limite para se pensar o Brasil. Não mais organizadas, canonizadas, parte de uma nomeação legitimada por saberes e poderes institucionais, acadêmicos ou midiáticos. Nascem, portanto, como experiências marginais, bastardas, que buscam escreviver o Brasil a partir de deslizamentos por entre as entranhas dos cânones, e, ao mesmo tempo, de delírios, psicodelismos, próprios de sujeitos que investiram em enxergar o mundo para além da dobra que os articula a uma realidade imposta (DELEUZE, 1991).

\section{Referências}

BEZERRA, Amílcar Almeida. Movimento Armorial $\times$ Tropicalismo. V Enecult - Encontro de Estudos Multidisciplinares em Cultura, Salvador, 27 a 29 de maio de 2009. p. 01-13.

BRITTO, Jomard Muniz de. Bordel brasilírico bordel: antropologia ficcional de nós mesmos. Recife: Comunicarte, 1992.

Encontros. Organização: Sergio Cohn. Rio de Janeiro: Beco do Azogue, 2013.

CALADO, Carlos. Tropicália: a história de uma revolução musical. São Paulo: Editora 34, 1997.

CASTELO BRANCO, Edwar de Alencar. Pernambucália: outras verdades tropicais. Revista Eletrônica da Anphlac, n. 06, p. 68-88, 2007.

Todos os dias de Paupéria: Torquato Neto e a invenção da Tropicália. São Paulo: Annablume, 2005.

COELHO, Frederico. Eu, brasileiro, confesso minha culpa e meu pecado: cultura marginal no Brasil nas décadas de 1960 e 1970. Rio de Janeiro: Civilização Brasileira, 2010.

DELEUZE, Gilles. A dobra: Leibniz e o barroco. Tradução: Luiz B. L. Orlandi. Campinas: Papirus, 1991.

DIDIER, Maria Thereza. Emblemas da sagração armorial: Ariano Suassuna e o movimento armorial (1970/76). Recife: UFPE, 2000.

DUARTE, Rogério. Tropicaos. Organização: Narlan Ramos, Mariana Rosa e Sergio Cohn. Rio de Janeiro: Azogue, 2003.

FOUCAULT, Michel. A ordem do discurso: aula inaugural no Collège de France, pronunciada em 2 de dezembro de 1970. Tradução: Laura Fraga de Almeida Sampaio. São Paulo: Loyola, 1996. 
Isto não é um cachimbo. Tradução: Jorge Coli. São Paulo:

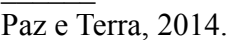

HALL, Stuart. A identidade cultural na pós-modernidade. Tradução: Tomaz Tadeu da Silva e Guacira Lopes Louro. Rio de Janeiro: Lamparina, 2014.

OLIVEIRA, Aristides; BEZERRA, Amílcar. Nos trópicos de Pernambucâncer: intelectuais sobre a cultura brasileira em trânsito nos anos 60/70 em Recife. Desenredos, ano IV, n. 15, Teresina, p. 01-16, nov.-dez. 2012.

REIS FILHO, Daniel Aarão. Ditadura e democracia no Brasil: do golpe de 1964 à Constituição de 1988. Rio de Janeiro: Zahar, 2014.

SARTRE, Jean-Paul. O existencialismo é um humanismo. São Paulo: Abril Cultural, 1973.

SPINK, Mary Jane P.; MEDRADO, Benedito. Produção de sentidos no cotidiano: uma abordagem teórico-metodológica para análise das práticas discursivas. In: SPINK, Mary Jane P.(Org.). Práticas discursivas e produção de sentido no cotidiano: aproximações teóricas e metodológicas. São Paulo: Cortez, 1999. p.41-61.

\section{Discografia}

ZÉ, Tom. Tropicália Lixo Lógico. São Paulo: Natura, 2012. 1 disco sonoro.

\section{Filmografia}

TROPICÁLIA. Direção: Marcelo Machado. Brasil, 2012, 87 min. son. color.
UMA NOITE EM 67. Direção: Renato Terra e Ricardo Calil. Brasil, 2010, 93 min. son. color.

\section{Hemerografia}

BRITTO, Jomard Muniz de. O último dândi. Entrevista concedida a Carlos Adriano. Trópico, 2005. Disponível em: <http://www. revistatropico.com.br/tropico/html/textos/2604,2.shl>. Acesso em: 19 abr. 2015.

HOLANDA, Heloísa Buarque de. Poetas rendem chefes de redação (II). Jornal do Brasil, Coluna B. Rio de Janeiro, 12 nov. 1983.

O DIA. Som Brasil apresenta "Tropicália”. Teresina, p.23, 19 dez. 1997.

. Tropicália terá bloco no Carnaval baiano. Teresina, p. 21, 15 jan. 1998.

SUASSUNA, Ariano. Dostoiévski e o mal. Folha de S. Paulo, 28 set. 1999. Disponível em: <http://www1.folha.uol.com.br/fsp/ opiniao/fz2809199907.htm> Acesso em: 22 dez. 2014.

VELOSO, Caetano. Dostoiévski, Ariano e a pernambucália. Folha de S. Paulo, 02 nov. 1999. Disponível em: <http://www1.folha. uol.com.br/fsp/ilustrad/fq0211199915.htm> Acesso em: $22 \mathrm{dez}$. 2014.

\footnotetext{
Autor/Author:

FÁBio LeonARdo CASTELo BRANCo BRITo fabioleobrito@hotmail.com

- Doutor em História Social pela Universidade Federal do Ceará. Professor da Universidade Federal do Piauí, atuando nos níveis de graduação, no Campus Senador Helvídio Nunes de Barros, e pós-graduação, como professor do quadro permanente do Programa de Pós-Graduação em História do Brasil. Co-líder do GT "História, Cultura e Subjetividade" (DGP/CNPq), atuando nas linhas de pesquisa "História, arte e invenção: narrativas da história", "Teoria da História" e "Cultura Brasileira". É autor do livro Torquato Neto e seus contemporâneos: vivências juvenis, experimentalismos e guerrilha semântica, publicado

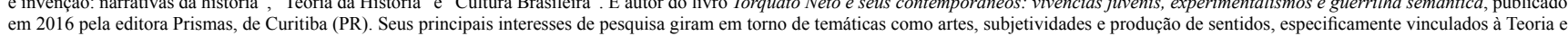
Filosofia da História e à História do Brasil Contemporâneo.

- Pilosofia da História e à História do Brasil Contemporâneo. level, as a permanent teatcher of the Graduate Program in Brazilian History. Co-leader of the "History, Culture and Subjectivity" GT (DGP/CNPq), acting in the research areas "History, art and invention narratives of history", "Theory of History" and "Brazilian Culture". He is the author of the book Torquato Neto e seus contemporaneos: vivencias juvenis, experimentalismos e guerrilha semântica, publishe in 2006 by Prismas, Curitiba (PR). His main research interests focus on themes like arts, subjectivities and production of meaning, specifically linked to Theory and Philosophy of History and to the History of Contemporary Brazil.
} 